\title{
Heteroskedasticity of Market Return: A Look at the All Nigerian Stock Exchange Index Time Series
}

\author{
Willi Iyiegbuniwe ${ }^{1}$, John E. Ezike ${ }^{1} \&$ Peter N. Amah ${ }^{1}$ \\ ${ }^{1}$ Department of Finance, University of Lagos, Lagos, Nigeria \\ Correspondence: John E. Ezike, Department of Finance, University of Lagos, Lagos, Nigeria. Tel: \\ 234-802-308-9125. E-mail: john_ezike@yahoo.com
}

Received: May 9, 2012 Accepted: June 6, 2012 Online Published: August 16, 2012

doi:10.5539/ijbm.v7n16p13 URL: http://dx.doi.org/10.5539/ijbm.v7n16p13

\begin{abstract}
With increasing importance of the capital market in the capital formation process, greater research interest is required towards understanding the behaviour of volatility and by extension, price generating dynamics in the market. Of the deluge of models that have emerged to explain and predict market behaviour, the pre-dominant ones are undoubtedly the unconditional mean-variance frameworks typified by the CAPM Class of models. Unfortunately these models have manifested critical defects in theory and evidence. This paper follows the lead of Engle (1982), Bollerslev (1986), and Nelson (1991) to model the All Nigerian Stock Exchange Index times series between January 2004 and December 2007 within the AR(3) EGARCH $(1,1)$ in-Mean framework with a view to explain those stylized facts of volatility like asymmetry, persistence, clustering, positive risk premium etc commonly associated with other advanced and rapidly developing markets.

Using 978 observations comprised in the weekly sample Index Return, the exponential model which tended to be white noise was found to be substantially well specified, and able to explain some of the puzzles thrown up by the normative frameworks as in Amah (2004). The research result shows that the market exhibited the phenomenon of mean/volatility persistence, a symptom typically associated with market inefficiency. Basically the auto-regressive scheme of the first and second moments provided the right basis to predict future behaviour of returns. There seems therefore to be a predictable component in the conditional variance over time such that increases in present volatility leads to subsequent increases in future volatility. This also suggests that the market has what analysts have come to know as long memory and slow auto-correlation decay rate which contradicts the intuition behind random walk hypothesis. Finally research findings suggest that the market did not exhibit 'leverage effects', a phenomenon of volatility asymmetry found in most advanced markets.
\end{abstract}

Keywords: heteroskedasticity, volatility, persistence, asymmetry, auto-regressive

\section{Introduction}

\subsection{Background}

The increasing importance of financial markets in the allocation mechanism of most economies raises concerns about the level and pattern of volatility of financial time series. Investors and policy makers are particularly interested in the dynamics of asset price fluctuation and efficiency of the markets which makes for optimal allocation of resources. Although conventional wisdom in the foundation of Finance has it that expected return is directly related to volatility, the dynamics of asset pricing as modeled within the normative framework reveals a number of defects. The conventional models of asset pricing proceed from the assumption of time varying mean, constant unconditional variance and Gausian distribution of returns with non-auto correlated residuals. But anecdotal experience and research seem to suggest the in-appropriateness of most of these assumptions (Hodricks and Zhang, 2001; Lynch, 2001; Amah, 2004; Frimpong \& Oteng, 2006). It could therefore be as a result of these potential sources of mis-specification that such traditional models as Capital Asset Pricing Model present pricing puzzles that cannot fully interpret the behaviour of expected returns. For so long, this meant a critical gap in theory and evidence.

However in the eighties, Engle (1982) and Bollerslev (1986) inspired the ARCH class of models which suggested that the missing link in the under-performance of the earlier frameworks can be located around volatility of asset returns. One key feature of asset prices is their stochastic nature, and there are times when they 
exhibit un-usual instability or we expect future variances to vary, a phenomenon captured by the concept of Heteroscedasticity. In this case we cannot expect the conventional models to appropriately explain the dynamics of price generating process. There is a pricing anomaly about the CAPM class of models that has not been able to reasonably explain the behaviour of expected returns. Infact in Amah (2004), it was suggested that using Nigerian evidence, systematic risk was only able to explain a negligible part of variation in asset returns just as 'residual risk' seemed more significant from the regression results. The result was significant over-valuation of capital assets especially those with high beta. This is contrary to the normative framework of the price generating process and also suggests over-whelming impact of 'shocks' in the determination of market prices. Meanwhile several later day research papers have successfully modeled these shocks which mean that continuing reliance on the traditional models in the determination of securities prices, risk management and derivatives trade could be misplaced. For the Nigerian market, the unfortunate implication is that there exists a gap in the decomposition of these 'Shocks' making it difficult for operators to fully understand the theoretical basis for asset pricing. Hence it becomes difficult to also understand and price-in some of those stylized facts commonly associated with volatility in the more intensely researched markets, namely volatility asymmetry or leverage effects, leptokurtosis, and long memory.

Perhaps the lack of understanding of the nature and bahaviour of volatility has limited the use of such exotic instruments as derivatives and hence, development of the market.

Like similar topics in empirical finance, volatility literature is dominated by studies of the advanced markets of Europe and America with quite a handful on the Asian markets. Without doubt however, empirical investigations into volatility of prices in African markets are comparatively few with few extant studies in published domain (for example Frimpong \& Oteng, 2006; Ogum, Beer and Nouyrigat, 2002 and 2005; and N'dri, 2007). The need to fill this gap is particularly imperative in this period of fast paced development of the Nigerian capital market and global market turbulence. This gap, particularly in the Nigerian literature raises some important but related questions that need to be answered in modeling asset prices, namely:

- Does the market offer appropriate compensation for risk faced by investors in the market?

- Do past volatility have significant power to explain/predict future market direction?

- Are there opportunities for trade provided by the nature of conditional variance exhibited by the market?

Research results on asset pricing that recognizes the variability of conditional variance are said to be superior to those that assume homoskedasticity of returns. Hence a successful modeling of volatility will improve our ability to explain and predict returns. With enhanced knowledge of the nature and behaviour of volatility, market participants will be in a better position to develop several trading and risk hedging instruments and strategies which will further lead to greater efficiency of the market. More importantly this study will further integrate Nigerian evidence into the main stream of global research on volatility-based asset pricing.

The theoretical framework of this paper revolves around one limitation of the normative asset pricing models the assumption of constant variance. Accordingly most of the literature reviews are taken from the ARCH family of models founded on Engle (1982), Bollerslev (1986) and several emerging developments in literature.

The empirical aspect of the study is limited to data on the Weekly All Nigerian Stock Exchange Index time series for the period covering January 2003 to December 2007 giving rise to a total of 978 observations. It is expected that the scope is wide enough to robustly answer the research questions and achieve the objectives set out for the paper.

\subsection{Study Objectives}

This paper follows the lead of later generation of asset pricing frameworks to model conditional variance of returns in the Nigerian Stock Exchange with a view to reach good understanding of the behaviour and nature of volatility in a typical developing market. More specifically the study seeks to find out if there is predictable component in the equity market index volatility process, whether the market index reveals appropriate risk premium and also determine whether the market exhibit asymmetric response to 'shocks'. These will enable a comparative view with research results in mainstream literature. Using the outcome, the paper will subsequently make appropriate prescription to policy and practice of pricing and risk management. Following a casual survey of literature and review of Nigerian capital market, we hypothesize that the market exhibits patterns in which past volatility is a significant predictor of future volatility. Accordingly we intend to argue in this paper that the market exhibits patterns that predispose it to abnormal returns by discernible investors.

The rest of the paper is organized as follows: section two reviews theory and literature of volatility, sections three threats methodological issues including model diagnostics and techniques of analysis. In section four, the 
authors present the data and regression results with some discussion of results while section five summarizes and concludes the paper.

\section{Overview of Theory and Empirical Literature}

The literature of asset pricing is replete with numerous specifications of return generating process. A number of such models as Capital Asset Pricing Model (CAPM), Arbitrage Pricing Theory (APT) and Black-Scholes Option Pricing Model (BS-OPM) are some of the economic constructs that have attracted considerable consensus. What perhaps is unanimously agreed is that they are all risk-return processes formulated on some strong market efficiency assumptions. The key assumption of interest here is that of constant variance or homoskedastic returns. Hurn and McDonald (1996) held that most of the conventional models yield errors with non-constant variance when fitted to economic time series data. This belief in time-varying variance spurred a re-examination of theory and evidence, and has given rise to a class of volatility-based frameworks which appear to have done better in explaining fluctuations witnessed in asset prices.

\subsection{Models of Conditional Variance}

Relationships that tend to model risk in the return generating process beyond the conventional models that utilize primary descriptive tools of unconditional standard deviation and beta did not receive sufficient attention in literature until the landmark works of Engle (1982) and Bollerslev (1986) which resulted in the ARCH family models of volatility. Their important contribution to the body of knowledge is that variation in volatility of an economic time series can be econometrically specified and predicted rendering un-necessary the usual assumption of constant error variance made in traditional regression analysis. Infact Lamoureux and Lastrapes (1990) and Bera and Higgins (1993) provided evidence that rate of information arrival in the market is time-dependent and gives rise to heteroskedastic returns.

Intuitively it can be said that volatility reflects degrees of investor uncertainty and such uncertainties have roots in information regarding fundamentals of the economy. In one key study of economic time series, Andersen, Bollerslev, Diebold and Wu (2005) found time varying volatility in response to industrial production and growth. Periods of economic growth (decline) were found to be associated with low (high) volatility. These studies provided justification for later day focus on volatility based models and this paper dwells essentially on the ARCH family of models. But firstly it would be helpful to appreciate this class of models and the intuition behind them.

GARCH simply means Generalized Auto-Regressive Conditional Heteroskedasticity. It is an up-dated form of Auto-Regressive Conditional Heteroskedasticity (ARCH) earlier formulated by Engle (1982). The focus of these models is on variance of error terms or impact of shocks to financial time series. In typical ordinary regression analysis, cases of non-homoskedastic time series returns are said to yield imprecise measures of standard errors and confidence intervals though the coefficient may remain unbiased. To rely on such analysis would require complicated error correction procedures.

The conditional auto-regressive models do not see this as a problem to be corrected but as economic phenomenon to be modelled. This would mean a determination of volatility metrics for use in such decision making areas of portfolio selection, foreign exchange trading, interest rates management, risk management and derivatives trading. Such focus will definitely prove superior in the determination of risk premium.

In order to understand these models, no weights are pre-assigned to these deviations; instead the weights are parameters to be determined. In this way amplitudes of returns over time are captured as future values of volatility closely relate to previous values. In the $\mathrm{ARCH}(\mathrm{P})$ process, variance of a random variable in the auto-regressive lag order of $\mathrm{p}$ at time $\mathrm{t}$ is thus made to depend on past variances in the form:

$$
\sigma_{t}^{2}=\alpha_{0}+\alpha_{l} \varepsilon_{t-1}^{2} \ldots \ldots+\alpha_{p} \varepsilon_{t-p}^{2}
$$

where $\sigma_{\mathrm{t}}^{2}=$ conditional variance at time $\mathrm{t}$

$\alpha_{0, \ldots} \quad \alpha_{\mathrm{p}}=$ positive constants

$\varepsilon_{\mathrm{t}-1, \ldots}^{2} \varepsilon_{\mathrm{t}-\mathrm{p}}^{2}=$ random variables of lag order $\mathrm{p}$ with zero mean and $\sigma^{2}$ variance

Roberto, Favaro and Cazaroto (2000) believe that a large number of lags are required to arrive at reasonable estimates of the parameters and this informed generalization of the process into GARCH by Bollerslev (1986). Under the Generalized Auto-Regressive Conditional Heteroskedasticity (p, q), the market conditions its expectations on past conditional variance (q order) and shocks ( $p$ order) as follows: 


$$
\sigma_{\mathrm{t}}^{2}=\alpha_{0}+\sum_{\mathrm{i}=1}^{\mathrm{p}} \alpha_{\mathrm{i}} \varepsilon_{\mathrm{t}-\mathrm{i}}^{2}+\sum_{\mathrm{i}=1}^{\mathrm{q}} \beta_{\mathrm{i}} \sigma_{\mathrm{t}-\mathrm{i}}^{2}
$$

where $\beta_{\mathrm{i}}$ represent parameters of conditional variance of the lag order $\mathrm{q}$.

With the generalized model, lags of a lower order are considered sufficient to proceed with analysis. However two common criticisms of the original GARCH framework are it's non-negativity assumption which imposes unnecessary constraint in the time path of shocks and volatility processes and the symmetric assumption. With this constraint, the model will not be able to capture some of those stylized facts observed in volatility literature, the key one being volatility asymmetry or leverage effects.

A number of variants of the model have been formulated to overcome this weakness but the most outstanding seem to be the Exponential Generalized Auto-Regressive Conditional Heteroskedasticity (EGARCH) proposed by Nelson (1991). Infact Piesse and Hearn (2002) suggest that this is a suitable model for analyzing African data due to heavy presence of asymmetry. Not surprisingly the few isolated studies that focused on the continent utilized EGARCH (see Alagidede and Panagiotidis, 2006; Frimpong and Oteng-Abayie, 2006; N'dri, 2007; and Ogum, Beer and Nouyrigat, 2002 \& 2005). Under the exponential process, the logarithm of conditional volatility is made to exponentially depend on the lag-log of asymmetry-adjusted innovation process and conditional variance, and may be expressed as follows:

$$
\ln \sigma_{\mathrm{t}}^{2}=\alpha_{0}+\sum_{\mathrm{i} / \mathrm{j}=1}^{\mathrm{p}}\left[\alpha_{\mathrm{i}}\left(\varepsilon_{\mathrm{t}-\mathrm{i}} \sigma_{\mathrm{t}-\mathrm{i}}^{-1}-\sqrt{2 \pi^{-1}}\right)+\alpha_{\mathrm{j}}\left(\varepsilon_{\mathrm{t}-\mathrm{j}} \sigma_{\mathrm{t}-\mathrm{j}}^{-1}\right)\right]+\sum_{\mathrm{i}=1}^{\mathrm{q}} \beta_{\mathrm{i}} \sigma_{\mathrm{t}-\mathrm{i}}^{2}
$$

where;

$\ln ($.$) is the natural log operator$

$\alpha_{\mathrm{i}}$ is the shocks coefficient

$\alpha_{j}$ is the asymmetry coefficient

$\beta_{\mathrm{i}}$ is the volatility persistence coefficient

$\varepsilon_{t}$ is the shock in the price process which may result to good or bad news $\varepsilon_{t} / \Omega \sim \mathrm{N}\left(0, \sigma_{t}^{2}\right)$

This is formulated in such a way that the innovation (whether positive or negative) will always produce positive conditional variance thereby rendering irrelevant the non-negativity assumption in the Symmetric GARCH process. Moreso the asymmetric response to innovation can be estimated.

\subsection{Volatility and Market Index Returns}

Theory generally predicts a positive relation between returns and volatility given that investors are risk-averse.

The stock market index is generally used as proxy for the market portfolio and its movement is said to approximate overall sentiments and direction of the market and the economy as a whole. Accordingly the index will typically aggregate consensus opinion of, and indeed reflect the fears and uncertainties faced by investors.

Several studies of index return time series have found what's been termed stylized facts of market behaviour. The key ones include leptokurtosis, excess skewness, slow auto-correlation decay, volatility clustering, and asymmetry or the so called 'leverage effect'. It is essentially for these behaviours that return distributions are non-normal and as such renders the conventional asset pricing models (with non-time varying error variances) inadequate - Frimpong and Oteng-Abayie (2006). Accordingly time-varying volatility based models are said to be superior in establishing the market dynamics.

\subsubsection{Volatility Asymmetry}

The dominant view in empirical research is that of differential impacts of negative (bad news) and positive (good news) shocks to the return process. Also known as 'leverage effect', this results from the fact that negative (positive) shock will typically depress (increase) equity price, increase (decrease) debt/equity ratio and increase (reduce) volatility metrics.

But a great number of these studies found negative asymmetry more prevalent in the more intensely researched advanced markets meaning that negative shocks give rise to higher volatility than equivalent unit of positive shock. Using the exponential model, Nelson (1991) suggested that volatility is higher in bear markets and this was explained by the tendency for investors to engage in panic selling at such times. Other studies that provided 
support for negative volatility asymmetry includes Black (1976), Christie (1982), Glosten et al (1993), Engle and Co (1993), Koutmos (1992). Notwithstanding these dominant research results, a few others found some rather contradictory, weak or no significant asymmetry coefficients. Interestingly majority of the contradictory findings relate to investigations into the African and other developing markets. Using weekly data for the period 1993-2000, Piesse and Hearn (2002) opined that univariate EGARCH model is suited for study of asymmetry but accepted the null hypothesis of no volatility asymmetry. In a study of the Ghana Databank Stock Index over the 10 year period 1994 - 2004, Frimpong and Oteng-Abayie (2006) observed that asymmetry coefficient is positive but insignificant which ordinarily could have suggested that good news induce greater volatility. N'dri (2007) investigated the common Regional Stock Exchange (BRVM) of 8 countries of the French speaking West African Economic and Monetary Union between 1999 and 2005 and found a positive and statistically significant asymmetric coefficient. In a more recent study of equity price behavior in the Nigerian market, Amah (2011) found volatility asymmetry to significant and skewed more towards positive. This suggests that for the developing markets, market booms induce greater volatility than market declines and is explained by the view that investors believe that booms behave more like speculative bubbles.

\subsubsection{Long Memory of Volatility}

The thrust of efficient market hypothesis is that in a financial time series, coefficient of auto-correlation lag function will give insignificant result. Infact if the extreme view of random walk hypothesis holds, the market should lack memory absolutely leading to clear independence of error terms, a process classified to be "white noise'.

However the pre-dominant part of empirical literature reported results that suggest successive dependence or slow decay rate of auto-correlations of the volatility process of stock returns. This implies that the market has long memory as impact of shocks remains for a relatively long time.

In a rather surprising result, Andersen, Bollerslev, Diebold and Ebens (2000) used the Dow Jones Index and found persistence of auto-correlations as long as 120 lags of daily series. Asokan, Chenouri and Abbasili (2001) studied daily data for the period 1985 - 1996 and found a significant and well fitted auto-regressive model process. Fama and French (1988), Porteba and Summers (1988) and Jegadeesh (1990) reported results that provided support. Andersen, Bollerslev, Diebold and Wu's (2005) finding of slow mean reversion rate of volatility is also consistent with long run persistence.

Using African data, Frimpong \& Co (2006) rejects the Random Walk Hypothesis and found parameter estimates of the GARCH Model that suggest high degree of successive dependence. Infact the study suggests that auto-correlation in the series persists up to 28 lags. N'dri (2007) found persistence parameters that are high and close to unity, which also suggests that once volatility increases, it most likely will remain high for a while. Amah (2011) also arrived at a finding of slow decay rate of autocorrelation which was more severe for individual stocks than the market as whole.

\subsubsection{Volatility Clustering}

Another form in which financial time series persistence manifests is in the nature of changing amplitudes of volatility over time. Data from most of empirical literature suggests that any increase in volatility is more likely to be followed by high volatility just as reduced volatility is followed by lower amplitudes. This phenomenon known as volatility clustering, long recognized by Mandelbrot (1963), leads to contiguous periods of fluctuation and relative stability. Frimpong et al (2006) found significant auto-correlation of squared returns series and presence of clusters.

N'dri (2007) also found that 'the positive and statistically significant coefficient in both normal and t-distributions based models confirms presence of clusters.

\subsubsection{Other Stylized facts of Index Return Series}

The other stylized features that render the conventional asset pricing models implausible include skewness and kurtosis of return distributions. While the former indicate that data is more inclined to one side of the distribution, the later shows where distribution is characterized by fat tails with a significant number of outlier values. A normal distribution will typically yield skewness of zero and kurtosis of 3 .

Interestingly most financial time series data are not exactly normal and accordingly exhibit abnormal skewness and kurtosis characteristics. Long time ago, Fama (1965) detected abnormal tail in the behaviour of stock market returns. Virtually all the empirical studies reviewed in this paper also found non-zero skewness and excess kurtosis. However it should be noted that for portfolios, the skewness of component assets may not matter much for analysis. This is because a portfolio may be zero-skewed and symmetrical even where the assets are 
individually highly skewed. The relevant statistic for an asset instead is the measure of co-skewness.

\subsection{Volatility and Market Efficiency}

Conceptually volatility is a measure of uncertainty and a reflection of the pace at which the market compound innovations in the price generating process. In ex ante basis therefore, it reflects the existence of incomplete information concerning the future stream of cashflows. It also sign-posts aspects of psychology - fear, greed and sentiments which impact demand and supply of assets in the market. The situation is exacerbated by the tendency of the market to 'over-shoot' in response to innovation, a phenomenon captured by the over-reaction hypothesis (Chopra, Lakonishok and Ritter-1992)

The question therefore is whether the degree of volatility has any bearing with the level of market efficiency. Given the prevalence of asymmetry and uncertainty in less developed and less efficient markets (Piesse and Hearn, 2002), normative thinking is that such markets are expected to have higher volatility.

\subsection{Volatility and Trade}

People intuitively think of risk as bad but volatility provides good opportunity for investors to engage in profitable trade. Ironically the attempt by investors to exploit this opportunity results in further improvement of market efficiency. Perhaps apart from normal trade in underlying securities, two key areas that merit mention in this paper are short selling and derivatives trading.

Christopher, James and Ferri (2003) investigated short selling activities in the USA NASDAQ and found that short selling varies directly with share price volatility and that short selling appears to precede days of unusually high returns. There is of course no surprise as it just reflects the potential for positive spread that existed in the market during the study period.

As stated earlier, the existence of a mechanism to exploit this opportunity actually goes a long way to align asset values and improve efficiency. Jones and Lamont (2001) studied the 1926-33 bubble in the US Market and warned that stocks can be over-priced when short sale constraints bind.

Trading in derivative instruments thrive under the environment of volatility and ironically helps to minimize volatility in prices of the underlying assets. Apart from expanding the scope of tradable assets, it helps in the construction of hedge portfolios to better manage risk and also improve efficiency of the market.

\section{Research Design and Methodolgy}

This section deals with the critical issues of choice of sample data, variables, models and their methods of estimation, evaluation and validation. These are particularly crucial given that strong views on the implausibility of the conventional asset pricing frameworks revolve around anomalies of mis-specification and time-varying variance of residual terms.

\subsection{Description of Sample Data and Variables}

Sample data utilized here for research is the weekly observation of All Nigerian Stock Exchange (NSE) Index for the period January 2004 to December 2007. This consists of the relevant closing week figures which gave rise to 978 observations. The NSE Index is a value-weighted index and reflects changes in the value of equity securities from the 1984 base year. It is derived as follows:

$$
\text { All NSE Index }=\sum\left(N_{i t} \cdot P_{i t}\right) /\left(N_{i b t} \cdot P_{i b t}\right)
$$

Where: Nit $=$ Number of shares of firm $\mathrm{i}$ outstanding at time $\mathrm{t}$

$\mathrm{P}_{\mathrm{it}}=$ Market Price of security $\mathrm{i}$ at time $\mathrm{t}$

$\mathrm{N}_{\mathrm{ibt}}=$ Number of shares of firm $\mathrm{i}$ outstanding at base date

$P_{\mathrm{ibt}}=$ Market Price of security $i$ at base date

\subsubsection{Periodic Index Return $\left(\mathrm{R}_{\mathrm{t}}\right)$}

Using the index figures extracted from the daily official list of the Exchange, periodic index returns are calculated as proxy to the dependent variable in the conditional mean equation

$$
R_{t}=\text { Index }_{t} / \text { Index }_{t-1}-1
$$

This reflects value of changes in the index over time.

\subsubsection{Periodic Index Return Lags $\left(\mathrm{R}_{\mathrm{t}-\mathrm{I}}\right.$ where $\left.\mathrm{i}=1,2,3 \ldots \mathrm{n}\right)$}

These are Index Returns historically derived or pre-determined for the periods prior to estimation period. Lagged returns go into the mean equation to capture the auto-regressive impact of the analytical process. For purposes of 
this study, we initially limited the process to lag order of eight based on results of both the Akaike Information and Schwertz Criteria but eventually found out that lag order of three is sufficient to do the estimation.

\subsubsection{Conditional Variance $\left(\sigma_{t}^{2}\right)$}

This is the key volatility measure for study in this paper. Its value is said to be conditional on information set, up to the period t. It is thus the dependent variable of interest in the volatility model but explanatory in the mean process. It cannot be directly observed but derived conditionally as the time-varying variance of the error term of index return series.

In the mean process, it captures the proxy index of relative risk aversion.

\subsubsection{Error term $\left(\varepsilon_{\mathrm{t}}\right) \sim \mathrm{N}\left(0, \sigma^{2}\right)$}

This is the random variable that captures the impact of innovation or shocks in the price generating dynamics. It is assumed to be normally distributed with mean zero and time varying variance, $\sigma^{2}$

It comes to the dynamics as surprise which may be in the form of un-expected good or bad news. Through this variable which enters the process as lags, those stylized facts of volatility like clusters and asymmetry can be captured. Like the conditional variance, it cannot be directly observed but rather estimated from the mean process.

\subsubsection{Conditional Variance Lags $\left(\sigma_{t-i}^{2}\right.$ where $\left.i=1,2,3 \ldots . . n\right)$}

Lags of conditional variance are used to capture persistence of volatility. In this paper the order is limited to one. It has been suggested that the $\operatorname{GARCH}(1,1)$ order is sufficient to capture all the necessary volatility behaviours of interest here.

\subsection{Specification of the Model}

In most of literature, formulation of model of conditional variance has followed a system of equations consisting of both mean and volatility relationships (see Engle. 1982; Bollerslev, 1986; Nelson, 1991; N'dri, 2007; and Frimpong and Oteng-Abayie, 2006). It is therefore formulated as a structural model to simultaneously investigate the stylized facts of volatility and return generating dynamics. Essentially it is assumed in this paper that the relationships follow a variant of Nelson's (1991) exponential generalized auto-regressive conditional heteroskedasticity $(\mathrm{EGARCH})$ process as follows:

$$
\begin{gathered}
\ln \mathrm{R}_{\mathrm{t}}=\mathrm{a}_{0}+\sum_{\mathrm{i}=1}^{\mathrm{n}} \mathrm{a}_{\mathrm{i}} \ln \mathrm{R}_{\mathrm{t}-\mathrm{i}}+\partial \ln \sigma_{\mathrm{t}}^{2}+\varepsilon_{\mathrm{t}} \\
\ln \sigma_{\mathrm{t}}^{2}=\alpha_{0}+\sum_{\mathrm{i} / \mathrm{j}=1}^{\mathrm{p}}\left[\alpha_{\mathrm{i}}\left(\varepsilon_{\mathrm{t}-\mathrm{i}} \sigma_{\mathrm{t}-\mathrm{i}}^{-1}-\sqrt{2 \pi^{-1}}\right)+\alpha_{\mathrm{j}}\left(\varepsilon_{\mathrm{t}-\mathrm{j}} \sigma_{\mathrm{t}-\mathrm{j}}^{-1}\right)\right]+\sum_{\mathrm{i}=1}^{\mathrm{q}} \beta_{\mathrm{i}} \sigma_{\mathrm{t}-\mathrm{i}}^{2}
\end{gathered}
$$

(the terms are as defined sections 3.1 to 3.1.5)

\subsection{Estimation and Evaluation}

In order to estimate the parameters of the EGARCH in-mean structural model, recourse is taken to the Maximum Likelihood Estimation Method employing the iteration procedure of Marquart Optimization Algorithm (see Marquardt, 1963). This estimation method is considered necessary in order to take care of the potentially destabilizing effect that often occurs when endogenous variables also occur as explanatory variables within a simultaneous equation framework. The endogeneity of these variables suggests they are likely to be correlated with the random residual terms. Moreover, Maximum Likelihood method is said to be one of the most efficient estimation techniques in analyzing non-linear functions (see Koutsoyiannis, 1977).

In order to appropriately handle the computation complexities involved in this type of analysis, estimation is done with the aid of E-Views computer software version 6.

The evaluation of parameter estimates follows the usual procedures of theoretical apriori, statistical, and econometric criteria. Traditionally, the in-mean equation reduces to risk-return relationship such that the coefficient of conditional volatility measures the reward to risk ratio, just as the intercept term is analogous to the risk free return. However this is not of immediate interest in here.

As for the conditional variance equation which incorporates the subject variables in this paper, the intercept is taken to be a long run average level of volatility which expectedly should be positive. The shock parameters 
capture the stylized behaviours of clusters and asymmetry arising from innovations and may be positive or negative.

If $\alpha_{j} \neq 0$, the impact of innovation is asymmetric

If $\alpha_{j}>0$, positive news generate more volatility than negative news

If $\alpha_{j}<0$, negative news generate more volatility than negative news

$\beta_{\mathrm{i}}$ is the volatility persistence coefficient and effectively measures the weight attached to previous estimates of conditional volatility in determining current estimates. Theoretically if less than, but close to 1 , volatility is persistent and the market is said to have long memory.

Following related literature and preliminary observation of price trends in the Nigerian Stock Market, it is hypothesized here that successive price changes are temporally dependent in magnitude and direction. In order to test this hypothesis and further evaluate the statistical and econometric fit of the model, we rely on standardized coefficient of determination, standard error tests, Ljung-Box statistics, Jarque Bera normality statistic, Durbin-Watson statistic and F-statistic at 5\% level of significance.

\section{Data Analysis and Research Results}

\subsection{Descriptive Statistics of All NSE Index Returns}

Unconditionally, the market index return series shows some interesting characteristics. From figure 1, it could be seen that the mean return for the period covered is 0.001 , a value not substantially higher than zero. However there is an indication of relatively high risk with standard deviation of 0.009

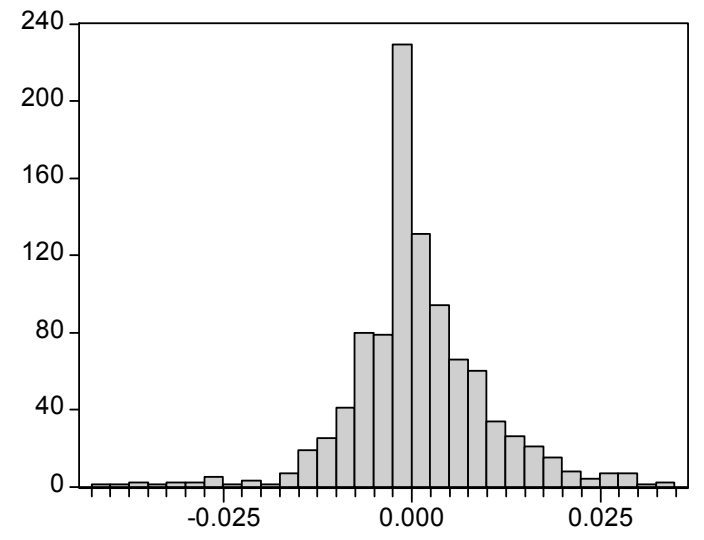

\begin{tabular}{|lr|}
\hline \multicolumn{2}{|l|}{ Series: INDEX_RETURN } \\
Sample 4978 \\
Observations 975 \\
Mean & 0.001078 \\
Median & $-2.15 \mathrm{E}-06$ \\
Maximum & 0.034737 \\
Minimum & -0.040584 \\
Std. Dev. & 0.009021 \\
Skewness & -0.064115 \\
Kurtosis & 5.892147 \\
& \\
Jarque-Bera & 340.4765 \\
Probability & 0.000000 \\
\hline
\end{tabular}

Figure 1. Descriptive statistics of NSE index return series for the period $2003-2007$

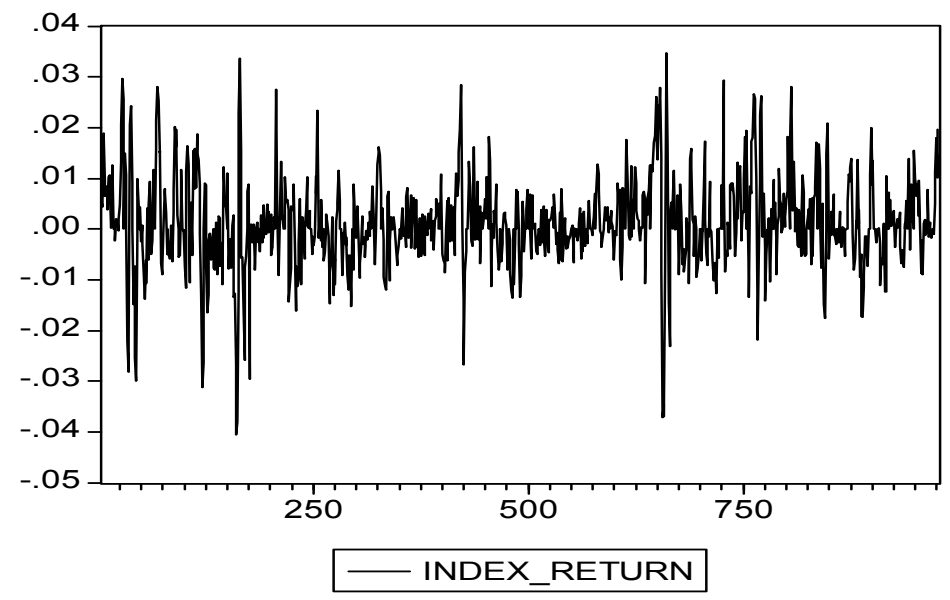

Figure 2. Graph of all NSE index return series 
The series represented in figures 1 and 2 showed slight negative skewness $(-0.064)$ which is again very close to zero, typically associated with symmetric distributions.

On the other hand, the data is leptokurtic with kurtosis of 5.89, which is above 3.00 for normally distributed series. This shows that the data is fat-tailed and regression coefficients may ordinarily exhibit some non-stable attributes of economic and research significance. Finally the Jarque Bera statistic of 340.48 with p-value of zero combines with the above figures to suggest strongly that distribution of the series is non-normal. Evidently these are signs that any application of the normative models, without some form of adjustment, would yield serious biases.

Table 1. Correlogram of the all NSE index return series

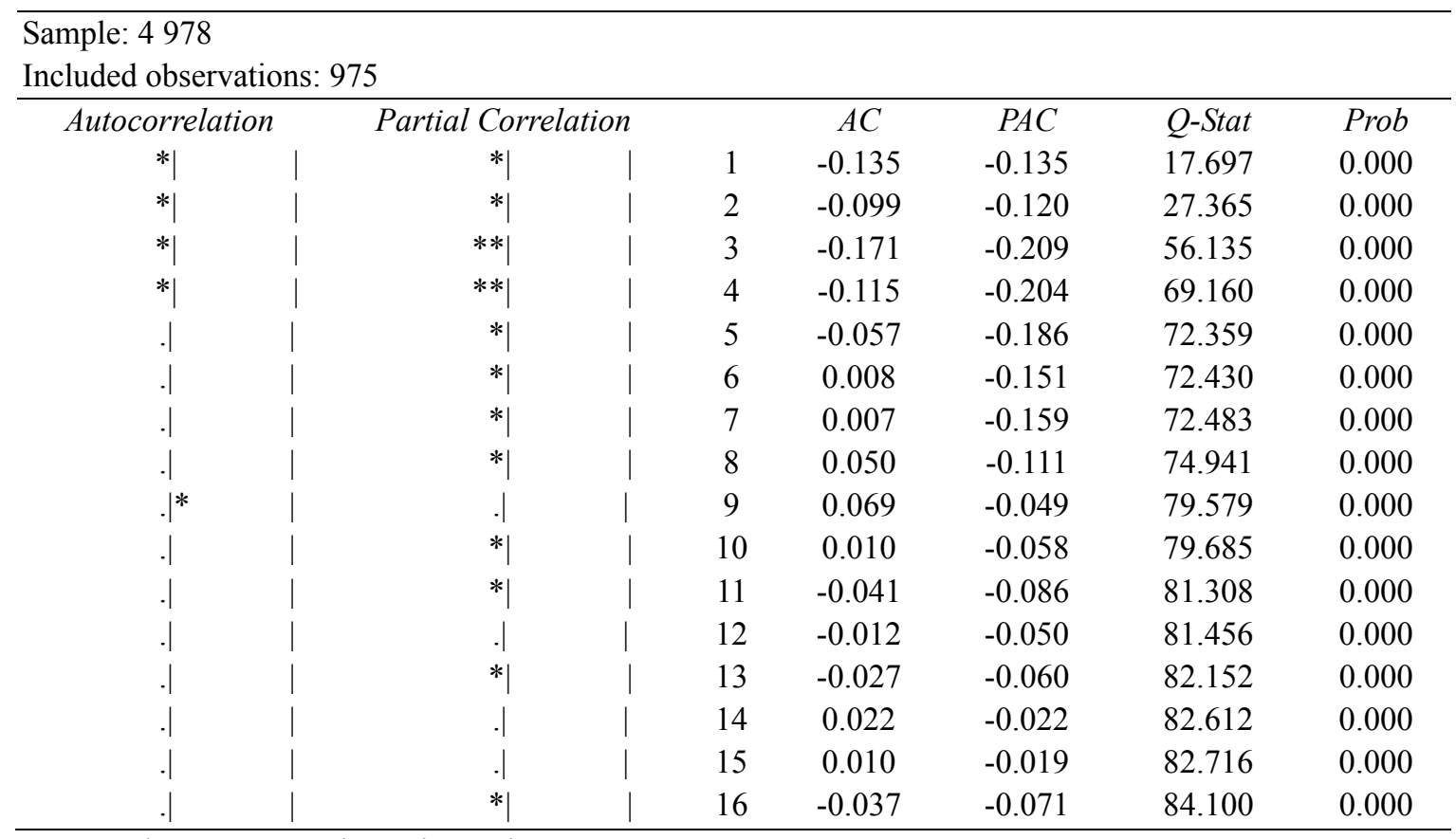

Source: Authors' computation using Eviews

A key item of interest in every volatility study is serial correlation in the relevant time series data. The raw index return series in table 1 showed strong presence of 'arch-effects' with Q-statistics that is statistically significant; having zero $p$-values in virtually all lags. This is one sign of inefficiency in markets where relevant information are not readily impounded in asset prices in a timely fashion. This is a further confirmation of the impotence of conventional mean-variance models in the price generating dynamics.

\subsection{Co-Movement of Variables}

In every regression operation, it is known that co-movement of the regressor-variables go a long way in influencing appropriate specification of the model, as it creates the mnlti-colinearity problem.

Table 2. Variance-covariance matrix

\begin{tabular}{cccccccc}
\hline & $\sigma_{t}^{2}$ & $R_{t-1}$ & $R_{t-2}$ & $R_{t-3}$ & $\varepsilon_{t-i} \sigma_{t-i}{ }^{-1}-\sqrt{ } 2 \pi^{-1}$ & $\varepsilon_{t-j} \sigma_{t-j}{ }^{-1}$ & $\sigma_{t-1}^{2}$ \\
\hline$\sigma_{t}^{2}$ & 88.951 & & & & & & \\
$R_{t-1}$ & -0.0824 & 0.0012 & & & & & \\
$R_{t-2}$ & -0.0421 & -0.0005 & 0.0016 & & & & \\
$R_{t-3}$ & -0.0091 & $-1.76 E-07$ & -0.0005 & 0.0011 & & & \\
$\varepsilon_{t-i} \sigma_{t-i}{ }^{-1}-\sqrt{ } 2 \pi^{-1}$ & -0.0338 & 0.0005 & 0.0001 & -0.0001 & 0.0035 & & \\
$\varepsilon_{t-j} \sigma_{t-j}^{-1}$ & 0.0173 & $-7.31 E-05$ & 0.0003 & $-3.35 E-05$ & -0.0007 & 0.0013 & \\
$\sigma_{t-1}^{2}$ & 0.0821 & $-8.31 E-05$ & -0.0005 & $7.31 E-05$ & -0.0009 & -0.0002 & 0.0017 \\
\hline
\end{tabular}

Source: Authors computation using Eviews 
It is clearly indicative from the variance-covariance matrix in table 2 that all the variables reasonably moved independent of each other. Infact all pairs of variables have approximately zero covariance except those involving conditional volatility. Even at that, the highest covariance it had was just about 0.08 which is very low. Hence, it does not appear apriori, that including any of the variables in the structural model constrains efficiency of the parameter estimates.

\subsection{Diagnostics of Standardized Residuals}

Before looking at nature of parameter estimates produced by this study, it is important to preview the econometric attributes of the standardized residuals and squared residuals in order to ascertain the level of confidence to repose on the model estimates, and perhaps compare it with descriptive characteristics of the raw series.

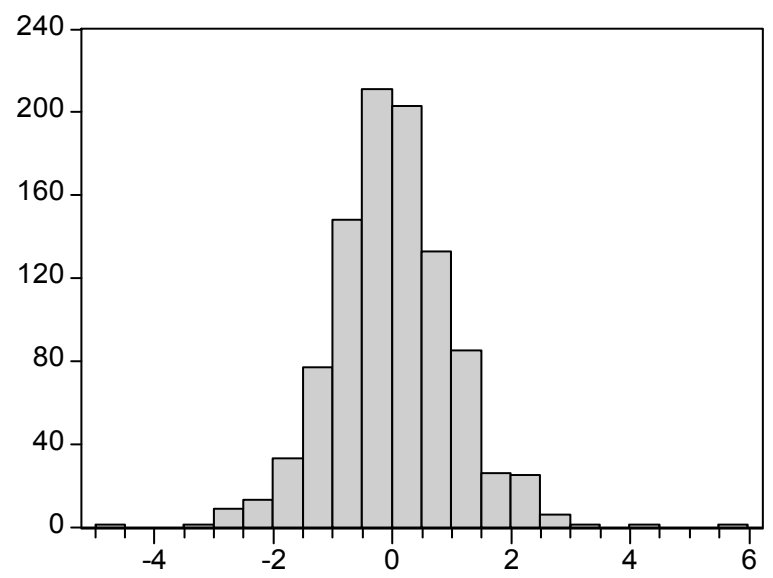

\begin{tabular}{|lr|}
\hline \multicolumn{2}{|l|}{ Series: Standardized Residuals } \\
Sample 5 978 \\
Observations 974 \\
Mean & 0.006370 \\
Median & -0.011870 \\
Maximum & 5.581481 \\
Minimum & -4.540969 \\
Std. Dev. & 1.001226 \\
Skewness & 0.199433 \\
Kurtosis & 4.712171 \\
& \\
Jarque-Bera & 125.4277 \\
Probability & 0.000000 \\
\hline
\end{tabular}

Figure 3. Model diagnostics - standardized residuals

Table 3. Model diagnostics - correlogram of standardized residuals

\begin{tabular}{|c|c|c|c|c|c|c|}
\hline Autocorrelation & Partial Correlation & & $\mathrm{AC}$ & PAC & Q-Stat & Prob \\
\hline. $\mid$ &. & 1 & 0.054 & 0.054 & 2.8127 & 0.094 \\
\hline .1 &. $\mid$ & 2 & 0.035 & 0.032 & 3.9897 & 0.136 \\
\hline. $\mid$ &. $\mid$ & 3 & 0.025 & 0.021 & 4.5961 & 0.204 \\
\hline. $\mid$ &. $\mid$ & 4 & -0.026 & -0.029 & 5.2377 & 0.264 \\
\hline. $\mid$ &. & 5 & -0.007 & -0.006 & 5.2888 & 0.382 \\
\hline. $\mid$ &. $\mid$ & 6 & 0.016 & 0.019 & 5.5560 & 0.475 \\
\hline. $\mid$ &. $\mid$ & 7 & 0.017 & 0.017 & 5.8340 & 0.559 \\
\hline. $\mid$ &. $\mid$ & 8 & 0.034 & 0.031 & 6.9659 & 0.540 \\
\hline. $\mid$ &. $\mid$ & 9 & 0.040 & 0.035 & 8.5472 & 0.480 \\
\hline. $\mid$ &. $\mid$ & 10 & 0.041 & 0.035 & 10.206 & 0.423 \\
\hline .1 &. $\mid$ & 11 & 0.001 & -0.006 & 10.206 & 0.512 \\
\hline .1 &. $\mid$ & 12 & -0.009 & -0.011 & 10.287 & 0.591 \\
\hline .1 &. $\mid$ & 13 & -0.027 & -0.026 & 11.014 & 0.610 \\
\hline .1 &. $\mid$ & 14 & -0.004 & 0.000 & 11.033 & 0.683 \\
\hline .1 & .1 & 15 & 0.015 & 0.016 & 11.253 & 0.734 \\
\hline .1 & .1 & 16 & -0.036 & -0.040 & 12.540 & 0.706 \\
\hline
\end{tabular}

Source: Authors computation using Eviews 
Table 4. Model diagnostics - correlogram of squared residuals

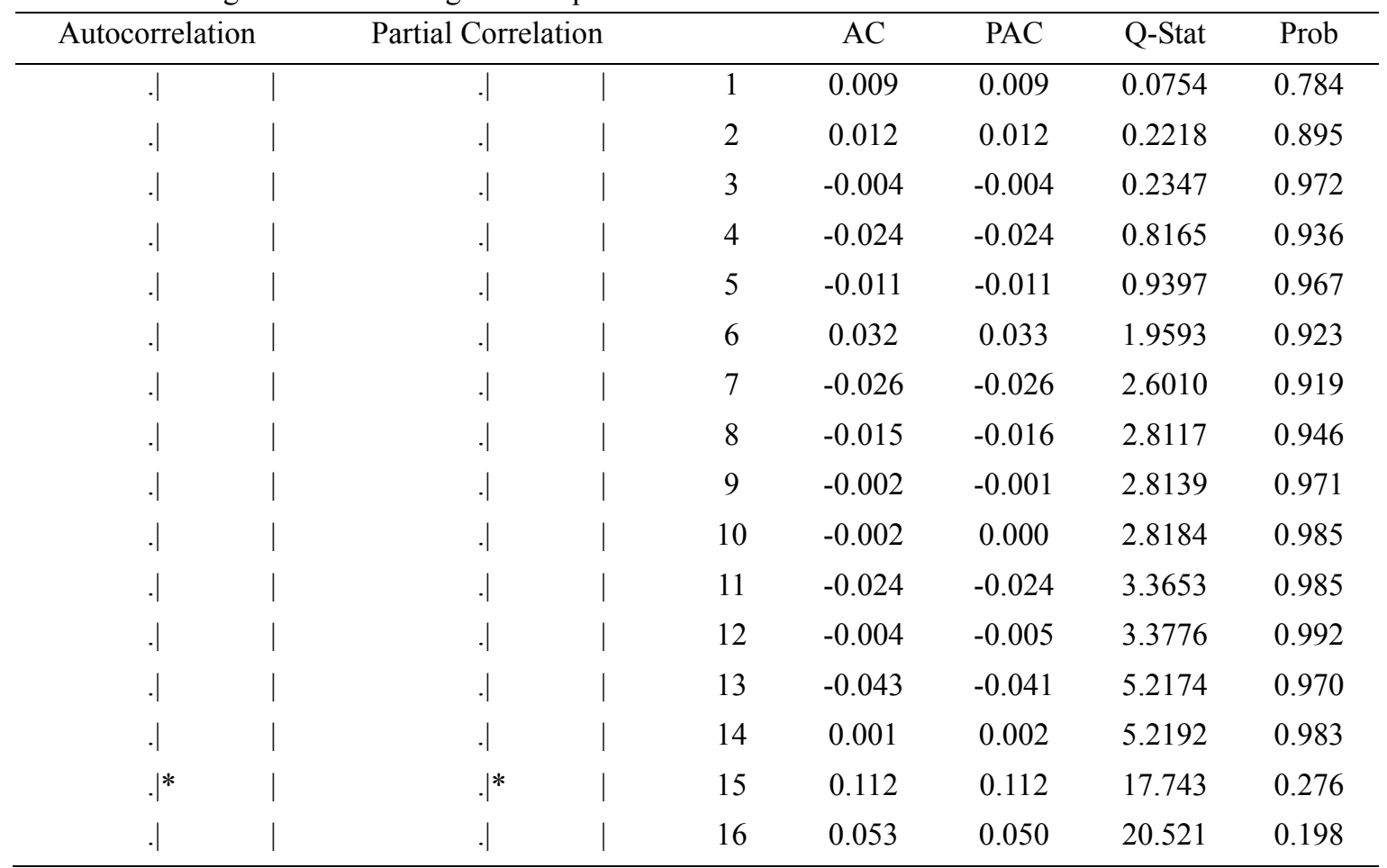

Source: Authors computation using Eviews

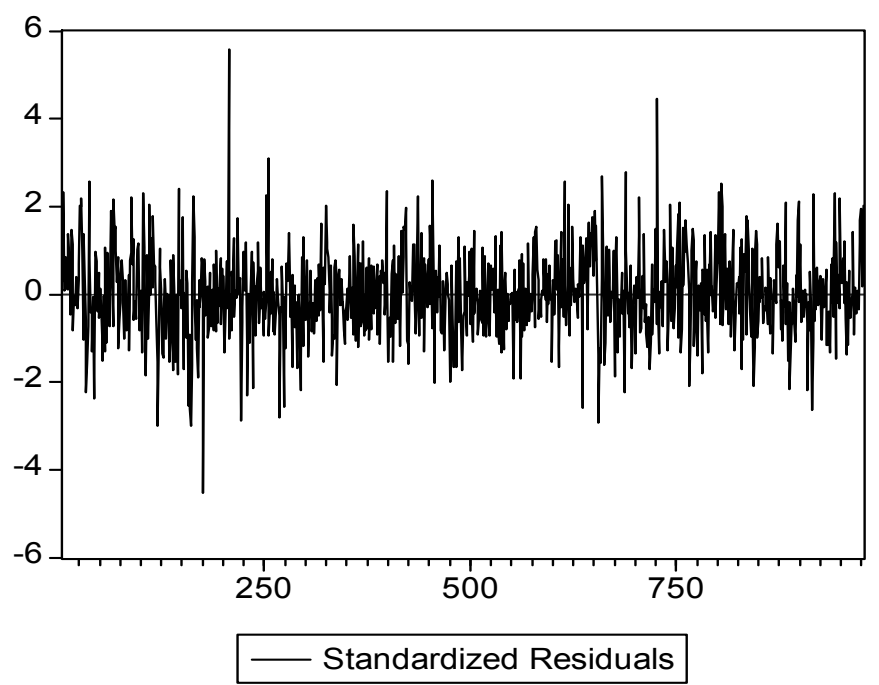

Figure 4. Graph of standardized residuals

The results of diagnostics of standardized residuals (see tables $3 \& 4$ ) reveal attributes that are quite different from the Index Return Series. With mean value 0.006 against 0.001 of the series, it is not surprising that standard deviation of the former at 1.001 was substantially above 0.009 for the series showing greater amplitude of changes.

However the key attributes of greater importance for analysis here relate those that determine serial dependence. All statistics of interest showed that the standardized residuals are closer to white noise and normality, and free from 'Arch Effects' compared to the raw series suggesting that the AR(3) EGARCH in-mean model is substantially well specified. In the case of the various tests of serial correlation, the results suggest that the regression residual series are completely free of dependency at $5 \%$ level of significance with auto-correlation and partial auto-correlation figures close to zero. Hence, the Ljung-Box Q statistic was insignificant in most lags 
with all p-values above 0.05 . The insignificance of Q statistics implies acceptance of null hypothesis of no serial correlation. Similarly, analysis of squared residuals suggests that conditional variance part of the equation is well specified. The requisite correlogram reveals auto-correlation and partial auto-correlation not significantly different at $5 \%$ significance level. This is confirmed by p-values that tended to unity in virtually all lags. Interestingly both serial correlation/dependence tests in the case of raw return series showed significant Ljung-Box statistics in all lags at $5 \%$ level of significance.

The implication of the results of above model diagnostics is that explanatory variables of the model should be able to account for substantial amount of variation in index return series.

\subsection{Parameter Estimation Results}

The estimates of parameters of the AR-EGARCH model of the All Nigerian Stock Exchange Index Return Series show some interesting results when compared to conventional mean-variance paradigm and research findings in the advanced markets and other parts of the developing world.

Table 5. The empirical results summary for AR(3)-EGARCH(1,1) model of all NSE index return series January 2004 - December 2007

\begin{tabular}{lccc}
\hline & Coefficient & Standard Error & P-Value \\
\hline $\mathrm{a}_{0}$ & 0.00037 & 0.00047 & 0.4332 \\
$\mathrm{a}_{1}$ & 0.4481 & 0.0349 & 0.0000 \\
$\mathrm{a}_{2}$ & 0.0511 & 0.0394 & 0.1941 \\
$\mathrm{a}_{3}$ & -0.0915 & 0.0337 & 0.0067 \\
$\partial$ & 3.9528 & 9.4314 & 0.6751 \\
$\alpha_{0}$ & -1.3463 & 0.4285 & 0.0017 \\
$\alpha_{\mathrm{i}}$ & 0.3292 & 0.0594 & 0.0000 \\
$\alpha_{\mathrm{j}}$ & 0.0468 & 0.0365 & 0.1997 \\
$\beta_{\mathrm{i}}$ & 0.8897 & 0.0415 & 0.0000 \\
$\mathrm{R}^{2}$ & $30.19 \%$ & & \\
Adjusted $\mathrm{R}^{2}$ & $29.61 \%$ & & \\
SSR & 0.0553 & & \\
DW & 1.71 & & \\
LL & 3458.40 & & \\
AIC & -7.0777 & & \\
SC & -7.0377 & & \\
F-Statistic & 52.1610 & &
\end{tabular}

Notes: $\mathrm{R}^{2}$ is the coefficient of determination, DW - Durbin Watson statistic, LL - Log Likelihood function value, AIC Akaike Information Criteria, SC - Schwertz Information Criteria. Coefficients are evaluated at $5 \%$ level of significance.

Source: Authors Computation using Eviews

\subsubsection{Auto-Regressive Behaviour of Index Return Series}

The AR(i) in-mean equation of the structural model has important twin objectives. The first is to capture the auto-regressive behaviour of the series. On this, as shown in table 5, the study found a positive and significant first order auto-regressive scheme. With a positive coefficient of 0.4481 and p-value of zero, we reject the null hypothesis of $a_{i}=0$. This suggests that stock market prices in a week are positively and significantly related to preceding weeks' prices.

However, although the second order auto-regression resulted in a positive coefficient of 0.0139 , it lacked significance at $5 \%$ level leading to acceptance of null hypothesis. This may be interpreted to mean that information about returns two weeks ago would not be expected to have a stable form of relationship with 
current returns and perhaps would not have much predictive value. But the third order lag resulted in negative but significant estimate suggesting that it can be readily predicted that increase in returns now is associated with decline in three weeks time.

This is perhaps a consequence of mean reversion tendency of prices especially after an initial over-reaction to some financial events.

It must additionally be noted that a number of similar studies suggested that if the market is efficient, the auto-regressive parameters should all lack statistical significance. Where they are significant, it is often partly explained by asynchronous trade in securities (see Amah, 2011). In most developing markets, several in-active stocks abound.

\subsubsection{Volatility Risk Premium}

One of the most pervasive theoretical constructs in Finance is the positive relationship between the first and second moments of returns distribution. The estimation of the structural model, in accordance with this intuition resulted in a positive coefficient (3.9528) which however was not significant at $5 \%$ level of significance. Hence we are compelled to accept the null hypothesis of zero index of relative risk aversion. This surprising outcome could suggest that investors did not necessarily conform to any systematic risk aversive behaviour and as such may have either taken risks that are not compensated for, or received more compensation than commensurate risks undertaken. Statistically the study revealed no definite pattern of relationship between conditional mean and volatility as the resulting magnitude and sign of coefficient may not be sustained.

\subsubsection{Volatility Persistence}

The persistence parameter, otherwise known as the GARCH term, showed a positive coefficient of 0.89 , a value that is relatively high and close to unity. Statistically, it proved to be significant leading to rejection of null hypothesis of $\beta=0$ at $5 \%$ level of significance. Significantly, it would suggest that there is a predictable component in the conditional variance over time such that increases in present volatility leads to subsequent increases in future volatility. This also suggests that the market has what analysts have come to know as long memory which contradicts the intuition behind random walk hypothesis. Another interesting aspect of this research result is that strength of persistence dominates the immediate impact of good or bad news in the short run and in a way lends some support to the concept of over-reaction hypothesis (Chopra et al, 2002)

\subsubsection{Nature of Response to Volatility Shocks}

The innovation in the exponential adjustment of the GARCH model is the separation of differential responses of positive and negative shocks to conditional volatility. Firstly the first shock parameter, $\alpha_{1}$ which measures the absolute impact of standardized residuals resulted in positive and statistically significant coefficient of 0.3292 . Accordingly we reject the null hypothesis of $\alpha_{1}=0$. Ordinarily this means that magnitude of standard residual is associated with magnitude of rise or fall of volatility in direct proportion. Hence large residuals tended to stimulate corresponding magnitude of conditional volatility, giving rise to a form of clusters of price fluctuation. Closely related to the above is the differential impact of different signs of the residuals. The asymmetric response of shocks is measured by the parameter $\alpha_{2}$, which in the study resulted in a positive but statistically insignificant coefficient of 0.0468 . The positive coefficient should ordinarily imply that good news or unexpected positive surprises lead to higher volatility than bad news or unexpected negative surprise of equal magnitude. But because this finding lacked significance, we accept the null hypothesis of zero coefficients which suggests that there is no discernible impact of good and bad news to changes in prices in a systematic sign-discriminating pattern. This obviously contradicts 'negative' results reached in a number of advanced markets on the nature of asymmetric response to surprises. This has one or two things to say about differences in behaviours of investors in the two markets.

\subsubsection{Overall Statistical Fit}

Generally the model employed resulted in satisfactory outcomes with F-Statistics of 52.161 (p-value 0.00000). The model could therefore be said to have captured important explanatory variables. Adjusted coefficient of determination of about $30 \%$, log-likelihood of 3458.40 and results of standardized residual tests show satisfactory results compared to similar studies reviewed.

\subsection{Discussion of Results}

A central issue in the theory of finance involves the determination of price generating dynamics. Because of the general belief in the positive relationship between risk and expected return in the price process, it is considered pertinent to incorporate the mean equation as control factor within the GARCH structural framework for correct 
specification. A by-product from the mean equation in this paper is the significant first and third order auto-regressive process. This appears not to be an isolated result. Lo and Mackinlay (1988), Ogum, Beer and Nouyrigat (2002), N'dri (2007) arrived at similar results that disproved the random walk hypothesis. However Frimpong and Oteng-Abayie (2006) found significant auto-regressive parameters in only the mean equations of Random Work, Symmetric GARCH and Threshold GARCH models whereas that of the Exponential GARCH proved insignificant in all lags. A better specified and more efficient model evidently means more confidence in the conditional mean and volatility process. The EGARCH model has been held out to be the most appropriate in analysing mean-volatility behaviours of developing markets (see Piesse and Hearn, 2002). Hence the result here implies strong faith in the existence of predictable component in the AR(1) and AR(3) processes.

But the more critical outcome of the mean return analysis is the lack of significance of conditional volatility. Although it turned out positive as expected, the fact of statistical acceptance of null hypothesis is indicative of unstable risk behaviour of the average investor in the Nigerian Capital Market. It would appear that at times, he tended to take more risk for less than commensurate expected return (perhaps out of fear), and on other occasions seek more compensation than the corresponding risk undertaken (perhaps out of greed). Such behaviours are often symptomatic of environments where investors rarely base their decisions on fundamentals and help to stoke market volatility. Hamilton (2001) and Shefrin (2007) situate this kind of behaviour within the framework of Psychology and Behavioural Finance rather than rational expectations. Aggarwal, Inclan and Leal (1999) found that such fears and greed are associated with local events, for example, the Mexico Peso crisis, the Indian Exchange scandal and the hyper-inflation in the Latin America. The one global event they recognized was the October 1987 crash in the USA which increased downside volatility around the globe. Backus and Gregory (1993) infact showed that there is no monotonic relation between volatility and risk premium. To them, it could be 'proportional, increasing or decreasing'. In an earlier isolated comparative study, Ogum et al (2005) found a positive and significant risk premium for Nigeria and a negative and insignificant outcome for Kenya.

The strong persistence of volatility dynamics found in this paper underlies the strength of fear and greed that often holds sway in the market. The study found that in most cases once volatility sets in, even contemporaneous surprises by way of unexpected good or bad news takes some time to reverse the established trend. Ogum et al (2005) also document similar statistical persistence of conditional variance in Nigeria and Kenya. N'dri (2007) found similar stationarity characteristics for the regional stock exchange of French speaking West African Economic Monetary Union called BRVM. Outside Africa, Chou (1988), Baillie and De-Gennaro (1990) had reported similar results.

The key innovation introduced into volatility study by the exponential model of Nelson (1991) is the asymmetric response to un-expected news of material significance. Although very close to zero, the asymmetry coefficient $\gamma$ found in this investigation is positive, which ordinarily could have meant that good news generate more volatility in the upside than bad news would do in the downside. However this result is not significant and suggests that once some structural factors set off spirals in the market, the sign of residuals play a minimal role in shaping the magnitude and direction of fluctuations. Some of such factors would seem to relate to regulation, political developments, seasonality, inflation and other macro-economic variables. This compares with the common view in literature as in Nelson (1991), Black (1976), and Pagan and Schwert (1990) that negative news inspire higher volatility than positive news of equal magnitude due to 'leverage effects'. Of the African based studies, Ogum et al (2005) reported asymmetry response for Nigeria as in most developed markets but positive form of asymmetry for the Kenyan market. Frimpong and Oteng-Abayie (2006) also did not find leverage-like response to shocks in Ghana. From the East European emerging market, Koutmos (1993) found positive asymmetry for Greece, Shields (1987) found no evidence of asymmetry in Poland and Philipines among others. It would appear that leverage effect is exclusively a phenomenon of markets at or nearing maturity while asymmetry either lacks significance or exists in positive form in most developing markets.

For Nigeria, what does this finding of positive but insignificant asymmetry tell about investor beliefs and behaviour?

This appears consistent with our earlier observation that it all boils down to a balance of fear and greed coupled with artificial barriers to price movement in administration of the stock market. And yet another factor could be located in the rate of information arrival and integrity of information in most emerging markets. Due to the known severity of information asymmetry in these markets, there is often initial apathy to new information of either sign. However, on balance, the tendency is for unexpected good news to generate higher volatility than bad news because investors think it more risky to accept, just as bad news is more likely to reflect the true state of affairs of a company. 
A related finding to the effect that magnitude of excess return is a positive and significant predictor of conditional variance has important implication to the price generating dynamics. If this is true, it means at least theoretically that an 'increase' in the surprise factor increases ex-ante volatility leading to expectation of high returns by investors. This is not surprising and hence a pervasive result in most of the empirical studies reviewed in this paper (see Ogum et al., 2002; Frimpong and Oteng-Abayie, 2006; N'dri, 2007; Aggarwal et al., 1999; and Baillie and De-Gennaro, 1990). This also gives some support to earlier finding in Amah (2004) to the effect that 'residual variance' dominates the market factor in the price generating process.

\section{Summary}

Understanding the behaviour of expected returns and volatility helps investors take the right decisions in capital assets trading and, policy makers, in formulating the policies to improve efficiency of the capital markets. A number of models have emerged to explain and predict price behaviour. However the pre-dominant unconditional mean-variance frameworks have manifested critical defects in theory and evidence. In an earlier study, Amah (2004), like several others before it found the residual risk factor significant in explaining time-varying mean returns, a puzzle that contradicts the normative basis for asset pricing. This paper followed the lead of Engle (1982), Bollerslev (1986) and Nelson (1991) to model the market within the context of AR(3) EGARCH $(1,1)$ in-mean framework. This has proved superior in explaining those stylized time series characteristics associated with capital markets such as volatility persistence, cluster and asymmetry.

\subsection{Summary of Findings}

1) The first and third order auto-regressive scheme proved significant in explaining conditional mean returns of the All Nigerian Stock Exchange Index time series. In order words, information embedded in the historical returns can be used to predict the future.

2) The paper found that conditional volatility possessed the right positive sign in the mean process. However it proved insignificant as a useful explanatory variable leading to acceptance of the null hypothesis of zero reward-to-risk proxy. N'dri (2007) arrived at similar outcome for the French West African Regional Exchange known as BRVM.

3) The auto-regressive process of the second moment provided right basis to explain conditional volatility into the future. Accordingly the test showed a very strong volatility persistence suggesting that large fluctuations are followed by equally large fluctuations and vice versa. Likewise, price fluctuation varies directly with magnitude of surprises or un-expected news (good or bad). These results appear to be pervasive in empirical evidence

4) Another remarkable outcome of analysis relates to sensitivity of volatility to sign of residuals. The regression resulted in a positive but low value of coefficient which suggested an incremental relation between unexpected good news and volatility relative to unexpected bad news of equal magnitude. This is in accord with findings from a number of developing markets, but contrary to dominant findings in advanced markets. However this result lacked significance at $5 \%$ level of significance which suggests that investors in the Nigerian market did not exhibit stable pattern of behaviour towards specific forms of unexpected outcomes such as may result from corporate actions.

\subsection{Conclusions}

1) The AR(3), EGARCH(1,1) in-mean model appears to be white noise and well specified with satisfactory econometric results especially with respect to attributes of standardized residuals. This provides support to the view that the framework is superior in modelling conditional mean and variance of returns especially in developing markets.

2) The nature of fear and greed may account for why fundamental factors do not appreciably drive the market. Hence in order to fully deconstruct the behaviour of the NSE Index time series, localized sources of investor greed and fear must be fully understood which means that analysis must extend to the realms of behavioural finance.

3) The average Nigerian Investor does not appear to price risk in a consistent manner but will typically show the tendency to follow the bandwagon in making portfolio choice.

4) Due to persistence of both the first and second moments of index return series, it is perhaps safe to conclude that opportunities exist from historical information in the Nigerian Stock Market to engage in profitable trade. A corollary to the above is that the market may not afterall be weak-form efficient. 


\subsection{Recommendations}

1) It would appear a misnomer that investors are not rewarded for taking risk in the capital market. As this could have arisen from the pattern of investment choice that borders on speculation, it is recommended that investors should rather pattern their choice to favour fundamental factors and hence reflect real economic prospects of component stocks on valuations. This calls for increased use of research and professional investment advice. Although this will not eliminate market fluctuations (being the hallmark of markets universally), it will serve to eliminate outlier swings in volatility that harm long run confidence in the capital market.

2) In the mean time, it is recommended that Investors and Fund Managers make use of volatility based models to take decisions. The existence of predictable components in these models implies that above average market average profits can be made by exclusive reliance on them.

3) Closely related to the above is the need for both operators and policy makers to put heads together to develop a derivatives market in Nigeria. Apart from providing opportunities for profitable trade, it enables the market evolve hedging instruments useful for risk management and hastens efficiency of the underlying market.

4) Because of manifestation of symptoms of inefficiency of the market, it is recommended that current efforts to remove factors that cause frictions in the market be intensified. Particularly, it is reckoned that transaction costs in the market remains one of the highest in the whole world and this has not helped in any way in developing the market. The existence of multiple taxes, fees, duties and commissions not only discourages investment but also distorts the allocation mechanism of the market. Moreover the problem of information asymmetry remains severe even in the face of greater corporate governance demands.

\subsection{Further Research}

The findings in relation to nature of risk premium and asymmetric response of volatility appear contradictory to traditional views. This suggests the need to investigate the relationship between psychological patterns and maximization of utility function of investors in the capital market. This will add tremendous value to the question of optimal investment choice.

Apart from this, empirical evidence comparing the performances of the different classes of models and different samples of the same index time series will help to improve the robustness of results reported in this paper and this merits further exploration.

\section{References}

Aggarwal R., Inclan C., \& Leal. R. (1999). Volatility in Emerging Markets. Journal of Financial and Quantitative Analysis, 34(1), 33-55. http://dx.doi.org/10.2307/2676245

Alagiede P., \& Panagiotidis T. (2006). Calendar Anomalies in an Emerging African Market: Evidence from the Ghana stock Exchange. Discussion Paper Series 13, Department of Economics, University of Loughborough.

Amah Peter N. (2004). An Investigation into the explanatory powers of 'Size Effects' and Residual Risk' in Cross Sectional Variation of returns in the Capital Market - The Nigerian Evidence. Unpublished Seminar Paper, Department of Finance, University of Lagos.

Amah Peter N. (2011). Multivariate Estimator of Volatility Patterns and Risk Return Trade-off in the Behaviour of Equity prices- The Nigerian Evidence. Unpublished Ph.D Thesis, Department of Finance, University of Lagos.

Andersen T., Bollerslev T., Diebold F., \& Wu G. (2005). A Framework for exploring the macro-economic determinants of systematic risk. American Economic Review, 95, 398-404. http://dx.doi.org/10.1257/000282805774669574

Andersen T., Bollerslev T., Diebold F., \& Ebens H. (2001). The Distribution of Realized Stock Return Volatility. Journal of Financial Economics, 61(1), 43-76. http://dx.doi.org/10.1016/S0304-405X(01)00055-1

Backus D., \& Gregory A. (1993). Theoretical Relations between Risk Premiums and Conditional Variances. Journal of Business and Economic Statistics, 11, 177-185. http://dx.doi.org/10.2307/1391369

Baillie R., \& De-Gennaro R. (1990). Stock Returns and Volatility. Journal of Financial and Quantitative Analysis, 25, 203-214. http://dx.doi.org/10.2307/2330824 
Bera, A., \& Higgins M. (1993). ARCH Models: Properties, Estimation and Testing. Journal of Economic Surveys, 7(4), 307-366. http://dx.doi.org/10.1111/j.1467-6419.1993.tb00170.x

Black F. (1976). Studies of Stock Market Volatility Changes. Proceedings of American Staistical Association, Business and Economic Studies Section, pp. 177-181.

Bollerslev T. (1986). Generalized Auto-Regressive Conditional Heteroskedasticity. Journal of Econometrics, 31, 307-327. http://dx.doi.org/10.1016/0304-4076(86)90063-1

Chenouri S., Abbasili M., \& Asokan M. (2001). ARCH and GARCH Models. A Project Report of the Department of Staistics and Actuarial Sciences, University of Waterloo, Canada.

Chopra N., Lakonishok J., \& Ritter J. (1992). Measuring Abnormal Performance: Do Stock Prices Over-React? Journal of Financial Economics, 31, 235-268. http://dx.doi.org/10.1016/0304-405X(92)90005-I

Chou R. Y. (1988). Volatility Persistence and Stock Valuations: Some Empirical Evidence using EGARCH. Journal of Applied Econometrics, 3, 279-294. http://dx.doi.org/10.1002/jae.3950030404

Christophe S., James B., \& Ferri M. (2003). A Close look at Short Selling in Nasdaq Market. Financial Analysts Journal, 59(6), 66-74. http://dx.doi.org/10.2469/faj.v59.n6.2576

Christie A. (1982). The Stochastic Behaviour of Common Stock Variances: Value, Leverage and Interest Rate Effects. Journal of Financial Economics, 10, 407-432. http://dx.doi.org/10.1016/0304-405X(82)90018-6

Engle R. (1982). Auto-Regressive Conditional Heteroscedasticity with Estimates of Variance of UK Inflation. Econometrica, 50, 987-1008. http://dx.doi.org/10.2307/1912773

Engle R., \& Ng V. K. (1993). Measuring and Testing the Impact of News on Volatility. Journal of Finance, 48, 1749-1801. http://dx.doi.org/10.2307/2329066

Frimpong J. M., \& Eric Oteng-Abayie. (2006). Modelling and Forecasting Volatility of Returns on the Ghana Stock Exchange using Garch Models. American Journal of Applied Sciences, 3, 2042-2048 http://dx.doi.org/10.3844/ajassp.2006.2042.2048

Fama E., \& French K. (1988). Permanent and Temporary Components of Stock Prices. Journal of Political Economy, 96, 246-273. http://dx.doi.org/10.1086/261535

Fama, E. (1965). The Behavior of Stock Market Prices. Journal of Business, 38, 34-105. http://dx.doi.org/10.1086/294743

Glosten L., Jagannathan R., \& Runkle D. (1993). On the Relation between the Expected Value and the Volatility of the nominal Excess Returns on Stocks. Journal of Finance, 48, 1791-1801. http://dx.doi.org/10.2307/2329067

Hurn, A., \& McDonald D. (1996). The size and power of four tests of detecting auto-regressive conditional heteroskedasticity in the presence of serial correlation.

Jegadeesh N. (1990). Evidence of Predictable behaviour of Security Returns. Journal of Finance, 45, 881-898. http://dx.doi.org/10.1111/j.1540-6261.1990.tb05110.x

Jones C. M., \& Lamont A. (2001). Short sale constraints and stock returns. University of Chicago Centre for Research on Security Prices (CRSP), Working Paper series 533.

Koutmos, G. (1992). Asymmetric Volatility and Risk-Return Trade-off in Foreign Stock Markets. Journal of Multinational Financial Management, 2, 27-43.

Koutsoyiannis, A. (1977). A Theory of Econometrics. London: MacMillan Press Ltd.

Lamoureux C., \& Lastrapes W. (1990). Persistence in Variance, Structural Change, and GARCH Model. Journal of Business and Economic Statistics, 8, 225-235. http://dx.doi.org/10.2307/1391985

Lo A., \& Mackinlay. (1988). Stock Market Prices Do not follow Random Walks: Evidence from a simple specification Tests. Review of Financial Studies, 1, 41-66. http://dx.doi.org/10.1093/rfs/1.1.41

Mandelbrot B. (1963). The Variation of Certain Speculative Prices. Journal of Business, 36, 394-419. http://dx.doi.org/10.1086/294632

Marquardt D. (1963). An Algorithm for Least Squares Estimation of non-linear Parameters. SIAM Journal of Applied Mathematics, ll, 431-441.

N'dri Konan L. (2007). Stock Market Returns and Volatility in the BRVM. African Journal of Business Management, 1(5), 107-112. 
Nelson D. (1991). Conditional Heteroskedasticity in Asset Returns: A New Approach. Econometrica, 59, 347-370. http://dx.doi.org/10.2307/2938260

Ogum G., Beer F., \& Nouyrigat G. (2002). An Empirical Analysis of Kenyan Daily Returns Using EGARCH Models. Paper presented at the Academy of Business Administration International Conference, Warsaw Poland.

Ogum, G., Beer, F., \& Nouyrigat G. (2005). Emerging Equity Market Volatility: An Empirical Investigation of Markets on Kenya and Nigeria. Journal of African Business, 1(2), 139-154.

Pagan A. R., \& Schwert G. (1990). Alternative Models on Conditional Stock Volatility. Journal of Econometrics, 45, 267-290. http://dx.doi.org/10.1016/0304-4076(90)90101-X

Piesse, J., \& Hearn B. (2002). Equity Market Integration versus Segmentation in the Dominant Markets of Southern African Customs Union: Co-integration and Causality Tests. Applied Economics, 34(14), 1711-1722. http://dx.doi.org/10.1080/00036840110119448

Porteba J., \& Summers L. (1988). Mean Reversion in Stock Returns - Evidence and Implications. Journal of Financial Economics, 22, 27-60.

Roberto O., Favaro G., and Cazarato, E. (2000). Gausian and Exponential GARCH Models. Institute de Fisica Sao Carlos, Universidade de Sao Paulo, Brazil, Working Paper.

Shefrin H. (2007). Beyond Greed and Fear: Understanding behavioural Finance and the Psychology of Investing. Financial Management Association Survey and Synthesis Series, Oxford University Press, New York.

Shields, K. K. (1997). Threshold Modelling of Stock Return Volatility on Eastern European Markets. Economics of Planning, 30(2/3), 107-125. http://dx.doi.org/10.1023/A:1003007708074

Schwert G. W. (1989). Why Does Stock Market Volatility Change Over Time. Journal of Finance, 44, 1115-1153. http://dx.doi.org/10.1111/j.1540-6261.1989.tb02647.x 